\title{
Tribological Effects of Graphene Oxide on Brake Friction Materials
}

\author{
Atirek Gaur, Saswati Nanda, Rajendra Kumar Duchaniya
}

\begin{abstract}
Many times in past Brake friction composites and their various combinations have been filled with graphene oxide made-up and tested many times for their tribological performance. Various changes in tribological behavior of testing materials of the frictional composites have been tested and evaluated on the setup of krauss testing machine During these testing's a high amount of enhancement in the friction performance $\left(\mu_{P}\right)$, frictions fade $\left(\mu_{F}\right)$ and friction recovery $\left(\mu_{R}\right)$ were found with the proper addition of graphene oxide in various amounts. The changes and the decrement in the wear performances and brake pad thickness loss were found with the increase in graphene oxide contents.
\end{abstract}

Keywords: Hummer's Method, Graphene Oxide, Wear, Friction, Nano- composite,

\section{INTRODUCTION}

Brake friction materials has allowed for the engineering of many types of specific tribological properties based on various combinations of binders, fillers, fibers and various friction modifiers for the materials [1]. Brake friction materials should always persuade a number of requirements which may able to sustain and able to give stable friction, superior wear resistance, less in noise and damping at wide range of testing temperatures, pressures and velocities [2, 3]. The role of binders and their modification, various fibers, different fillers and friction modifiers on the Tribology-performance of brake friction materials has been extensively studied in the literature [4-8]. In recent time many Nano-particulates as additives enables the polymer based composites to possess high performance, even many low filler fractions provide an massive quantity of some interfacial area through which the bulk properties of the composites can be alter [9-11]. Considering the fact that performance of friction material is mainly determined by the nature of the in- situ friction film formation [12, 13]. Large number of investigations has been conducted to see the effect of various nano-materials used for the tribological behavior of many polymer composites used in previous times, however the

Revised Manuscript Received on May 25, 2020.

* Correspondence Author

Atirek Gaur*, Student, Department of Metallurgical and Materials Engineering, Malaviya National Institute of Technology (MNIT), Jaipur, India.

Saswati Nanda, Student, Department of Metallurgical and Materials Engineering, Malaviya National Institute of Technology (MNIT), Jaipur, India.

Dr. Rajendra Kumar Duchaniya, Associate Professor, Department of Metallurgical and Materials Engineering, Malaviya National Institute of Technology (MNIT), Jaipur, India.

(c) The Authors. Published by Blue Eyes Intelligence Engineering and Sciences Publication (BEIESP). This is an open access article under the CC BY-NC-ND license (http://creativecommons.org/licenses/by-nc-nd/4.0/) these effects of tested nano-materials used for testing the tribo-performance of many brake friction applications are quite limited [14; 15]. So the present work shows and studied the various effects of graphene oxide and its various varying contents on the trio-bological performance of various brake friction materials.

\section{VARIOUS NEW FORMULATIONS AND GENERATION OF BRAKE FRICTION MATERIALS}

At the time of making various testing and for the writing this paper, we tested two new formulations relating to form friction and in terms of brake materials which exists and made by using the various subsequent ingredients like many forms of used Resin, $\mathrm{Fe}_{2} \mathrm{O}_{3}$, Steel composite fiber, Ceramic composite fiber, Organic fiber, Magnesium Oxide, many Aluminium Oxide, Barium, Sulphur, pure form of Graphite etc.

\subsection{Elements of New Formulations}

The nature used for the testing and precise for various compositions of the composite formulations is kept classified as academic assets. Scanning Electron Microscope is used to identify the formulations Yusli et al [16] and Table 1 given below provides the exact amount of elements present in the viable brake pads and in the amount of formulations present in A, B, C \& D. Table 1: Amount of elements present in all formulation by (\% weight) $[16,17]$.

Table 1 - Showing the composition of various elements of Brake Pad Materials

\begin{tabular}{|l|c|c|c|c|c|}
\hline Element & Commercial & $\mathrm{A}$ & $\mathrm{B}$ & $\mathrm{C}$ & $\mathrm{D}$ \\
\hline Carbon & 60.9 & 55.12 & 54.63 & 56.86 & 53.44 \\
\hline Oxygen & 8.2 & 18.89 & 13.14 & 20.6 & 12.84 \\
\hline Magnesium & 0.9 & 1.2 & - & 0.21 & 0.87 \\
\hline Aluminium & 0.4 & 2.36 & 0.83 & 1.69 & 1.32 \\
\hline Sulfur & 0.6 & 1.99 & - & - & 2.5 \\
\hline Iron & 25.6 & 20.44 & 27.43 & 16.06 & 20.45 \\
\hline Bariuim & 2.9 & - & 3.97 & - & 2.91 \\
\hline Copper & - & - & - & - & 5.97 \\
\hline Calcium & - & - & - & 2.16 & - \\
\hline Zinc & - & - & - & 2.42 & - \\
\hline
\end{tabular}

\subsection{EXPERIMENTAL}

Arrangement and the combination of graphene oxide was finished with setting up the Hummer's strategy which is exceptionally simple and admirable procedure of making GO and increasingly compelling rGO in enormous or modest quantity. graphene oxide (GO) was delivered by utilizing unadulterated type of graphite powder. Development of and getting the GO in powder structure Graphene oxide was made by including $25 \mathrm{ml}$ of sulfuric corrosive (H2SO4) what's more, $3 \mathrm{ml}$ of $\left(\mathrm{H}_{3} \mathrm{PO}_{4}\right)$ were blended and mixed for various minutes.

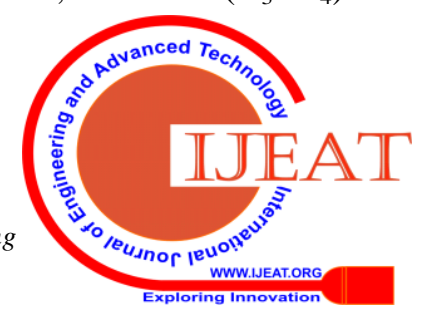


$0.25 \mathrm{~g}$ of unadulterated graphite powder was then included into and blended the arrangement by utilizing attractive mixing for blending for next couple of moments. $1.30 \mathrm{~g}$ of (KMnO4) was then included comfortable into the mixed arrangement.

Furthermore, blended ceaselessly for 6 hours until the arrangement changed to dim green, and the expulsion of high measure of $\mathrm{KMnO} 4$, was finished by including 0.645 $\mathrm{ml}$ (H2O2) was included gradually and again mixed for 10 minutes. $10 \mathrm{ml}$ of $(\mathrm{HCl})$ and $30 \mathrm{ml}$ measure of DI water (DIW) was then included and again centrifuged at 3000 rpm for next 30 minutes. Residuals were on the other hand washed with exceptionally thought $\mathrm{HCl}$ and DIW for 5 and more occasions. The disposed of GO arrangement was dried by a oven at $90{ }^{\circ} \mathrm{C}$ for 48 hours to turn out the ideal powder of GO. The contact materials were created utilizing a measure of graphene oxide by weight and after that these were manufactured. The handling conditions for the creation are given in the table 2 given below.

Table 2 - Fabrication of Composite

\begin{tabular}{|c|c|c|c|c|c|}
\hline $\begin{array}{c}\text { Feeder } \\
\text { RPM }\end{array}$ & $\begin{array}{c}\text { Chopper } \\
\text { RPM }\end{array}$ & Temp $\left({ }^{\circ} \mathbf{C}\right)$ & $\begin{array}{c}\text { Compres } \\
\text { sion }\end{array}$ & $\begin{array}{c}\text { Curing } \\
\text { Time }\end{array}$ & $\begin{array}{c}\text { Total } \\
\text { Duration }\end{array}$ \\
\hline $\mathbf{4 0 0}$ & $\mathbf{4 0 0 0}$ & $\mathbf{1 6 0}^{\circ} \mathbf{C}$ & $\mathbf{2 0 M p a}$ & $\begin{array}{c}\mathbf{5 2} \\
\text { minut } \\
\text { es }\end{array}$ & $\begin{array}{c}52 \\
\text { minutes }\end{array}$ \\
\hline
\end{tabular}

Post curing time was evaluated for 6hrs at the temperature of $180^{\circ} \mathrm{C}$ and the fade and recovery tests were done by using a Krauss type tester shown in the Figure1 [18].

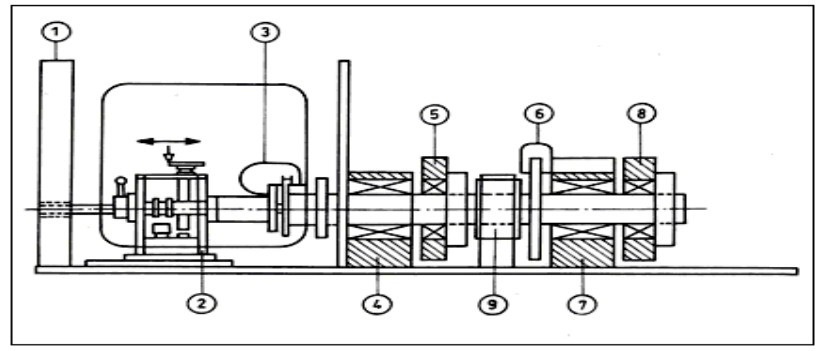

FIGURE 1. Schematic of Krauss testing machine for tribo- performance evaluation of brake-pads. (1) Compressed air supply (2) Bearings movable (3) Air inlet (4) Bearings (5) Option SH 2.5 kg-m ${ }^{2}$ (6) Emergency stop option (7) Bearings (8) Options SH 5 kg- $\mathrm{m}^{2}(9)$ Flywheel

\section{RESULTS AND DISCUSSION}

On the adding the various amount of graphene oxide the changes and the variation in $\mu_{\mathrm{P}}, \mu_{\mathrm{F}}$ and $\mu_{\mathrm{R}}$ were found and as the function of various contents of graphene oxide. during the testing we observed that the performance and recovery changes of $\mu$ remained comparatively as good for all four graphene oxide content.

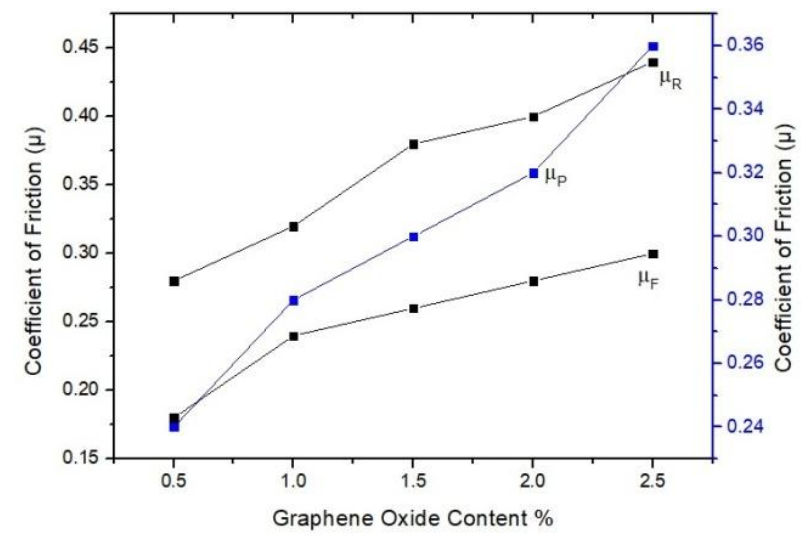

Figure 2. Friction curve of composites: $\mu_{P}(\mu-$ performance), $\mu_{F}\left(\mu\right.$-fade) and $\mu_{R}(\mu$ - Recovery) with graphene oxide contents.

The variation of $\boldsymbol{\mu}_{\mathbf{P}}, \boldsymbol{\mu}_{\mathbf{F}}$ and $\boldsymbol{\mu}_{\mathbf{R}}$ are shown in figure 2 by taking various contents of graphene oxide. It was found that the value of $\mu$ remained fairly and equivalent of all the four composites contents with graphene oxide.

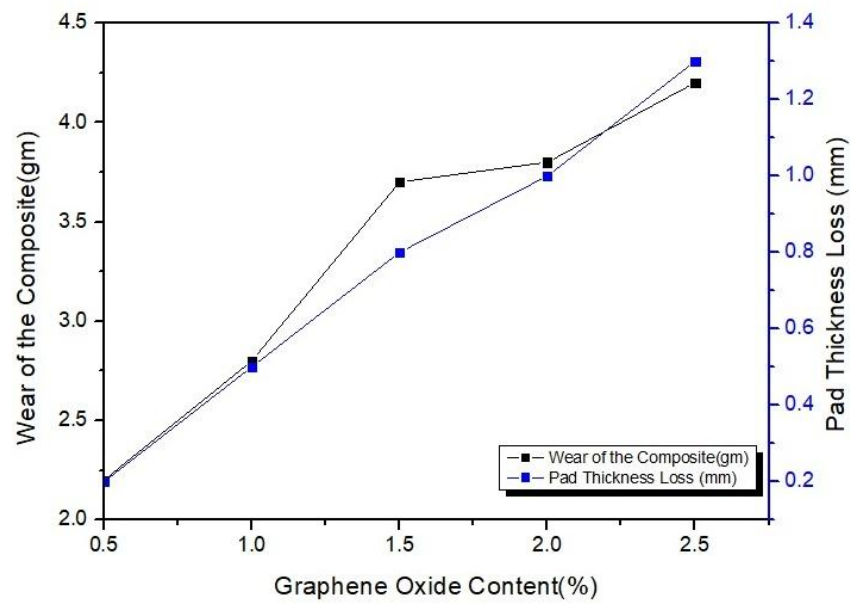

The wear as a utility of graphene oxide content is shown in figure 3, where the wear of the four investigated composites and disc increases as the graphene oxide content increased with corresponding decrease as the function of graphene oxide.

\section{CONCLUSION}

During the testing of wear increasing and various friction values for the brake friction material by using graphene oxide we concluded that as in increase of graphene oxide the wear of the composite increased and decrement in the thickness of brake pad found also the changes in the friction were slightly changeable and few reduction in friction were found.

\section{ACKNOWLEDGEMENT}

The author gratefully acknowledges the support and encouragement by their fellows and the supervisor.

\section{REFERENCES}

1. M.G. Jacko, S.K. Rhee and Kirk-Othmer, "Encyclopedia of Chemical Technology" vol. 4, 4th ed., Wiley, New York, 1992.

2. J. Bijwe, Polymer Composites 18, 378-396 (1997).

3. D Chan and G

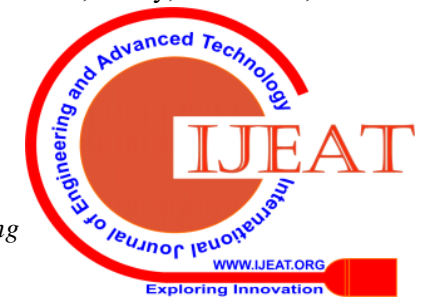


W.Stachowiak, Proc. Instn Mech. Engrs Vol. 218 Part D: J. Automobile Engineering 218, 953-966 (2004).

4. M. H. Cho, J. Ju, S. J. Kim and H. Jang, Wear 260 855-860 (2006).

5. K. H Cho, M. H. Cho, S. J. Kim and H. Jang, Tribology Letter 32, 59-66 (2008).

6. B. K. Satapathy and J. Bijwe, Journal of Reinforced Plastics and Composites 24, 563-577 (2005).

7. B. K. Satapathy and J. Bijwe, Wear 257, 573-584 (2004).

8. J. Bijwe, Nidhi, N. Majumdar and B.K. Satapathy, Wear 259(7-12), 1068-1078 (2005).

9. Guang Shi, Ming Qiu Zhang, Min Zhi Rong, Bernd Wetzel, Klaus Friedrich, Wear 254, 784-796 (2003).

10. L. Chang, Z. Zhang, C. Breidt and K. Friedrich, Wear 258, 141-148.

11. S. Bahadur and C. Sunkara, Wear 258, 1411-1421.

12. W. Österle and I. Urban, Wear 257, 215-226 (2004).

13. Peter Filip, Zdenek Weiss and David Rafaja, Wear252, 189-198 (2002).

14. Yiqun Liu, Zhongqing Fan, Hengyi Ma, Yigang Tan and Jinliang Qiao, Wear 261, 225-229 (2006).

15. H.J. Hwang, S. L. Jung, K. H. Cho, Y.J. Kim and H. Jang, Wear 268, 519-525 (2010).

16. 16) Yusli, M.J., Mohamad, I.I., Mazli, M., Mohd, A.S., Bakar, M. furthermore, Mohd, S.S., Fabrication and Morphology Study on Disk/Rotor Brake Pad, second Malaysian Brake Friction Materials Colloquium (2004),

17. 17) Mohamad, I.I., Yusli, M.J., Mazli, M., Mohd. A.S., Bakar, M., Mohd, S.S., Evaluation of Light Rail Transit Brake Pad Formulations, second Malaysian Brake Friction Materials Colloquium (2004),

18. [18] Amar Patnaik, Mukesh Kumar, Bhabani K. Satapathy, Bharat S. Tomar. " Performance sensitivity of hybrid phenolic composites in friction braking: Effect of ceramic and aramid fibre combination", Wear, 2010

\section{AUTHORS PROFILE}

Atirek Gaur is final year student of Masters of Technology in Department of Metallurgical and Materials Engineering at MNIT Jaipur, working in the field of nano coatings, graduated in Mechanical Engineering

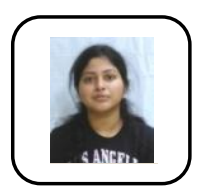

Saswati Nanda is final year student of Masters of Technology in Department of Metallurgical and Materials Engineering at MNIT Jaipur, graduated in Metallurgy and Materials Engineering and her working areas are coatings and High Entropy Alloys.

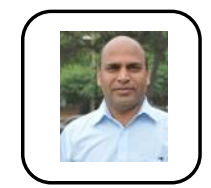

Dr. Rajendra Kumar Duchaniya is an Associate Professor in the Department of Metallurgical and Materials Engineering, Malaviya National Institute of Technology (MNIT), Jaipur. Having a great experience and research knowledge in the field of Nanotechnology, Surface Coating, Thin film Coatings.

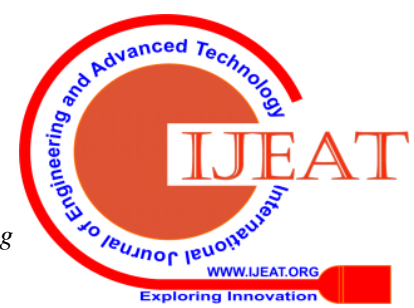

